\title{
Aplicabilidade da Inteligência Estratégica na Criação de uma Instituição de Ensino Superior
}

Ana Paula Cardoso Vieira ${ }^{1}$

\begin{abstract}
Resumo: A aplicação da Inteligência Estratégica ascende como diferencial competitivo entre as organizações. Usar Inteligência em prol de um negócio existente ou novo projeto possibilita uma visão abrangente e dinâmica dos mercados pertinentes e projeção de cenários mais assertivos, diminuindo riscos e incertezas. Em ascensão, o Setor de Educação cresce em competitividade, exigindo constantes inovações e investimentos. Neste contexto situa-se o Instituto A, uma instituição do segmento educacional que qualifica profissionais e almeja expandir seu negócio lançando-se como Instituição de Ensino Superior (IES). Em fase inicial do projeto, o objetivo deste trabalho é compreender a aplicabilidade da Inteligência na criação da IES. Foi realizada uma pesquisa qualitativa via estudo de caso, com entrevistas e observação participante. Resultados apontam que a Inteligência Estratégica é incipiente, mas fundamental para criação da IES, atrelando o monitoramento de mercado ao sucesso do projeto.
\end{abstract}

Palavras-chave: Inteligência Estratégica, Monitoramento, Conhecimento, Educação.

\section{Applicability of Strategic Intelligence in the Creation of a Higher Education Institution}

Abstract: The application of Strategic Intelligence rises as a competitive differential among organizations. Using Intelligence for an existing business or new project allows a holistic and dynamic view of relevant markets and the projection of more assertives scenarios, reducing risks and uncertainties. On the rise, the Education Sector grows in competitiveness, demanding constant innovations and investments. In this context the Institute A, an educational institution that qualify professionals and aims to expand its business by launching itself as a Higher Education Institution (HEI). In the initial phase of the project the objective of this work is to understand the applicability of Intelligence in the creation of Higher Education Institution. A qualitative study was conducted through a case study with interviews and participant observation. Results point out that Strategic Intelligence is incipient but fundamental for creating the HEI, linking the market monitoring to the success of the process.

Key words: Strategic Intelligence, Monitoring, Knowledge, Education.

\footnotetext{
${ }^{1}$ Possui graduação em Administração de Empresas pela Pontifícia Universidade Católica do Rio Grande do Sul (2012). Especialista em Inteligência Competitiva e de Mercado pela Pontifícia Universidade Católica do Rio Grande do Sul (2016). Tem experiência na área de Administração, Marketing e Marcado.
} 


\section{Aplicabilidade da Inteligência Estratégica na Criação de uma Instituição de Ensino Superior}

\section{Introdução}

Em um mercado acirrado e competitivo, a busca por informação está cada vez mais acessivel, com isso, a Inteligência nas organizações pode ser usada como uma ferramenta estratégica de alta competitividade com o propósito de observar e compreender o ambiente, transformando informações em ativos relevantes para a tomada de decisões assertivas, reduzindo riscos e incertezas (SANTOSA E RIBASB, 2017). Para Fuld (2007), Inteligência é o uso da informação de forma eficiente, compreendendo mudanças, orientando estratégias e agindo antecipadamente. Para tal, é necessário um processo estruturado, sem o qual a abordagem permanece incipiente ou extremamente informal.

O Setor Educacional cresce exponencialmente, em um mercado que nos últimos anos vem expandido em relação à concorrência e oferta de serviços. É uma indústria que impacta diretamente na economia e no desenvolvimento do país, gerando movimentos de mercado dinâmicos e constantes. Em um eixo do Setor Educacional, o Ensino Superior vem ganhando destaque no cenário competitivo, conforme MEC/INEP (2018), as matrículas no ensino superior cresce em média 4,6\% ao ano, finzalizando 2017 com 8,3 milhões de matrículas, em um cresciento de $3 \%$ em relação a 2016 .

Com o mercado aquecido e com barreiras apontadas em um cenário futuro, o Instituto A, já consagrado no mercado educacional, aderiu ao projeto de expansão passando de Instituto Qualificador para Instituição de Ensino Superior (IES). Um projeto ainda sigiloso para colaboradores e sociedade. Atento à movimentação do mercado, o Instituto compreende que acompanhar o ambiente no qual está inserido é fundamental, concordando com Heinze Janissek-Muniz (2018), um processo de monitoramento de ambiente através da Inteligência possa ser uma forma eficiente de reduzir incertezas e identificar cenários estratégicos para balizar decisões.

Tem-se assim o objetivo deste trabalho que é compreender a aplicabilidade da Inteligência na criação da IES do Instituto A, através dos objetivos especificos de identificar os processos de monitoramento e pessoas/setores envolvidos na Inteligência. Para tal, foi conduzido um estudo sobre Inteligência e seus principais conceitos aplicado ao cenário atual das IES; posteriormente foi compilada uma pesquisa qualitativa exploratória aplicada através de entrevistas com os diretores do Instituto A, além de observação participante de um dos autores desse estudo.

Este artigo apresenta em sua estrutura, além desta introdução, uma revisão da literatura visando sustentar conceitualmente o tema proposto, seguido do método utilizado e posterior análise dos resultados. Para finalizar, conclui-se o estudo, com sugestões de pesquisas futuras.

\section{Inteligência, Gestão da Informação, Gestão do Conhecimento}

Inteligência em latim significa saber estabelecer relações entre elementos com o propósito de formar um conjunto significativo; sabendo escolher ou eleger entre diversos elementos. Segundo Lesca e Janissek-Muniz (2015), Inteligência é, pois, a faculdade de conhecer, localizar, comparar, selecionar, associar e representar. Segundo Rios e JanissekMuniz (2014), Inteligência representa um conjunto de ações para localizar, obter, escolher, associar e usar de forma pertinente o conhecimento do ambiente da empresa. Nas organizações, a Inteligência é uma habilidade de visão diferenciada para auxiliar na tomada de decisão, tornando-se uma vantagem competitiva perante os concorrentes e posicionando-se de forma profícua no mercado (MARÓSTICA, 2014). A Inteligência é baseada em informações do 
ambiente relevante para as organizações, com intenção de um posicionamento competitivo no mercado, sendo uma das funções principais da Inteligência Estratégca o suporte para construção de cenários, formulando assim estratégias para que a organização mantenha-se competitiva no mercado (RECHE E JANISSEK-MUNIZ et al, 2018).

Segundo Rios e Janissek-Muniz (2014) existem diferentes conceitos de Inteligência, como: Inteligência empresarial; Inteligência estratégica organizacional; Inteligência estratégica antecipativa e coletiva; Inteligência de negócios ou business intelligence (BI), cada qual dando um enfoque diferente e complementar para monitoramento, direcionando os processos de implantação. Analisando a diversidade dos conceitos, entende-se que a Inteligência é alicerçada sob três principais pilares: processos, pessoas e tecnologia. Entendese que é preciso integrar, treinar e motivar pessoas para que realizem e compreendam plenamente os processos, buscando sua melhoria contínua, utilizando tecnologias adequadas como facilitadoras (VENKI, 2016). Del Massa, Damian e Valentim, (2018) complementam que as iniciativas voltadas para trabalhar o capital humano em sua potencialidade devem envolver comuncação, tecnologia, processos e aspectos de liderança, propondo assim a informação seja utilizada d maneira crítica, reflexiva, criativa, autônoma e ética em diferentes situações.

Para a ABRAIC (2016), as pessoas são as detentoras de informação e conhecimento, e devem manter-se incentivadas na busca, aprimoramento, aplicação e melhorias dos processos, assim como fazê-las enxergar as vantagens de compartilhá-lo com a organização. Davenport e Prusak (1998) afirmam que é preciso que o indivíduo seja considerado em suas dimensões individuais e sociais, pessoais e transcendentes, para o sucesso das organizações. Nesse contexto de dependência das pessoas nos processos de Inteligência, Kriaa, Janissek-Muniz e Lesca (2015) sugerem uma animação (motivação) com o intuito de manter vivo o processo na organização.

Conforme Del Massa, Damian e Valentim (2018), a tecnologia inicialmente objetivava desenvolver habilidades para o uso de bases de dados eletrônicas, entretanto, com a revisão de conceitos e da atual realidade, passou a assumir o papel de compartilhamento de informação e conhecimento como a competência essencial para o processo. A tecnologia é considerada fonte de alavancagem e otimização de processos, facilitando o acesso e a realização das atividades, não sendo um fator essencial, e sim arbitrário, que deve ser ponderado e usado de forma coerente aos objetivos da empresa. A tecnologia auxilia no armazenamento, processamento e disseminação de informações, provendo transparência e agilidade. Com suporte tecnológico adequado, o mapeamento de processos e sua modelagem se aproximam do real, diminuindo incertezas na tomada de decisão (VENKI, 2016).

A Inteligência como ferramenta estratégica é uma composição dos conceitos de Gestão da Informação (GI) e Gestão do Conhecimento (GC) (SANTOS E BARBOSA,2016). A informação representa a base e a razão para o início de um tipo novo de gestão, sendo considerado, juntamente com o conhecimento, um pilar decisivo para o sucesso de uma organização (CARVALHO e CASAGRANDE, 2009). Para Silva e Neves (2003), informação é a representação simbólica e codificada de acontecimentos, objetos e fluxos que constituem o real perceptível, podendo ser diferenciada por ter significado, propósito e relevância. Já o conhecimento, para Danvenport e Prusak (1998), é um combinado de experiências, valores, informações e insight experimentado, que proporcionam uma estrutura para avaliação e incorporação de novas experiências.

Contribuindo com o conceito de Inteligência, a Gestão da Informação (GI) é a aplicação de princípios administrativos à aquisição, organização, controle, disseminação e uso da informação para operacionalização efetiva nas empresas, bem como o gerenciamento de todo o ambiente informacional (TARAPANOFF, 2006). A informação, quando bem gerida, escolhida e empregada, acelera na empresa os processos de aprendizagem e colaboração 
(CHOO, 2003). Informações pertinentes e bem geridas são vistas como um ativo que proporciona vantagem competitiva nas organizações: elas podem ser adquiridas formalmente, provenientes de informações públicas, e/ou informalmente, adquiridas através de reuniões, conversas ou percepções, ambas sendo relevantes para a formulação de estratégias (STAREC, 2012). A informação ainda pode ser nivelada em organizacional e estratégica e as fontes podem ser de origem primária, secundaria e terciária, sugerindo diferentes graus de qualidade e confiabilidade da informação (CHOO, 2003).

Neste sentido, todas as informações podem ser importantes, mas nem todas serão relevantes para organização (GOMES e BRAGA, 2004). Para que a informação faça a diferença no processo decisório, além de atrelado a um significado, deve ser comunicada de forma organizada, possibilitando adquirir novos pontos de vista e interpretação de eventos, podendo ser considerada um meio de se extrair e construir conhecimento (DAVENPORT E PRUSAK, 1998). O conhecimento em si pode ser explícito e tácito (NONAKA e TAKEUCHI, 2008). O explícito pode ser expresso e compartilhado, enquanto o tácito corresponde aquele baseado em experiências pessoais, entendido como uma habilidade do indivíduo (TARAPANOFF, 2006). Não é facilmente visível e explicável, dificultando a comunicação e o compartilhamento. Somente a informação, ainda que bem organizada, não fornece novos insights. Assim, a Gestão do Conhecimento (GC) passou a ser trabalhada nas organizações como um ativo valioso para a organização, destacando-se nos processos gerenciais por facilitar os processos de criação, compartilhamento e uso de conhecimento individual e coletivo (STRAUHS, 2012).

Tanto a GI como a GC, quando bem geridas, contribuem para um melhor posicionamento estratégico e uma análise amplificada de mercado, valorizando os negócios. Enquanto a GC torna a organização mais forte e competitiva, alimentando o conhecimento de acontecimentos de sucesso já ocorridos, a GI coleta, armazena e dissemina conteúdos relevantes (DEL MASSA, DAMIAN E VALENTIM, 2018). Conforme Santos e Barosa et al (2016) relacionam-se estratégia, informação, conhecimento e inteligência, numa perspectiva sintética, em que a Inteligência Estratégica proporciona melhoria dos processos, aprimoramento do sistema, fortalecimento da cultura e criação de conhecimento.

Dentro do contexto deste trabalho, que aborda a aplicabilidade da Inteligência na criação de uma IES, é importante compreender o cenário pertinente, com a premissa de que a gestão de uma instituição de ensino, assim como quaisquer outras organizações, exige análises e posturas estratégicas. A Educação no Brasil permite várias discussões englobando, além do caráter social, econômico e político, a importância para o desenvolvimento do país como um todo. Com isso, o estudo mercadológico feito pelas IES deve ser recorrente e atual, sendo importante a constituição do processo de Inteligência de forma adequada e pertinente.

\section{Educação superior no Brasil}

O conhecimento e a capacidade de aprendizado são condições necessárias para o desenvolvimento humano, o que implica a necessidade de acesso à Educação (COSTA e COCHIA, 2013). A Educação tem como finalidade preparar indivíduos para o exercício de uma profissão, além de civilizar o aluno, incentivam a prática científica, formando a sua consciência político-social para que exerçam a cidadania. A educação superior é assunto relevante para o cenário nacional, por contribuir fortemente para o desenvolvimento do país; é pertinente pois, compreender o mercado e os fatores que contribuem para expansão do setor. O acesso aos níveis de Educação Superior no Brasil não é apenas uma exigência econômica, é também um indicador do grau de democracia e justiça social, sendo a educação superior um setor em crescimento, uma nova "área de negócios" (MEC, 2003). A afirmação, realizada em 2003, é válida perante o atual cenário brasileiro. Conforme o Censo de Educação (MEC/INEP, 2018) em 2017 concentrava-se cerca de 8,3 milhões de alunos matriculados, distribuídos em 2.448 IES., o 
memso ano 2017, contabilizou o aumento no número de ingressantes em $8,1 \%$ em relação a 2016, contabilizando cerca de 3,2 milhões de novos alunos, dados que evidenciam o crescimento exponencial na procura por formação superior.

$\mathrm{O}$ alto número de matriculados está diretamente relacionado a modalidade dos cursos, ensino à distância, cresceu cerca de 17,6\% de 2016 para 2017, enquanto a modalidade de ensino presencial aumentou 0,4\% no mesmo paríodo (MEC/INEP, 2018). Com o mercado de educação em evidência, especialmente a educação superior, cada vez mais se faz necessário um olhar atento sobre os cenários e movimentos que podem influenciar o setor. A Inteligência, como uma fonte estratégica e competitiva, possibilita uma visão abrangente e dinâmica, entretanto só será legítima se estruturada e organizada.

Cada vez mais as IES estão descobrindo seu caráter social e percebendo que precisam conquistar pela eficiência, qualidade, credibilidade e legitimidade junto à comunidade em que estão inseridas (VENTURINI et al, 2010). Muitos setores passam por uma reestruturação na tentativa de se adequar às constantes mudanças do ambiente (interno e externo): as IES também aderem a essa regra, pois necessitam de respostas aos acontecimentos externos e internos, sob o prisma de sobrevivência no mercado, conforme Carvalho e Casagrande (2009). Os gestores devem monitorar ameaças e oportunidades, nem sempre vistas de forma clara, e vislumbrar uma melhor vantagem competitiva, o que sugere a necessidade de processos de Inteligência instalados e funcionais.

Alguns estudos apontam práticas de Inteligência nas IES de forma incipiente. Em alguns casos analisados percebe-se que há falta de rotinas, sistemas ou gerenciamento nas instituições em relação à informação sobre o ambiente externo. Ainda, há relatos de que a informação quase sempre chega até o dirigente por um meio informal, através da sua rede de contatos internos ou externos à organização (LEITÃO, 2010), denotando falta de Gestão Informacional. Em outro estudo, Dalfovo, Schirmann e Correia (2011) apontam a necessidade de aprimoramento da Gestão do Conhecimento como um diferencial competitivo, emergindo a Inteligência nas IES de forma não estruturada, mas de absoluta relevância na tomada de decisão. Percebe-se, assim, os elos evidentes entre Gestão da Informação, Gestão do Conhecimento e Inteligência Estratégica, visto que tais atividades interdependem, exigindo um fluxo para sua existência e permanência nas organizações. Tais conceitos requerem se encontrar em uma estrutura organizada a fim de posicionar a instituição de forma competitiva, atrelando-se as pessoas envolvidas aos processos pertinentes e às tecnologias utilizadas, especialmente em um setor dinâmico e em franca expansão como o Setor de Educação no Brasil.

\section{Método de pesquisa}

Este trabalho caracteriza-se como uma pesquisa de caráter qualitativo que se justifica quando desejamos entender a natureza dos dados através da compreensão de fenômenos sociais ou determinadas situações complexas, a partir da realidade e da perspectiva das pessoas que dele participam (BRYMAN, 2000). Para Creswell (2014), a pesquisa qualitativa pressupõe o uso de estruturas interpretativas que informam o estudo dos problemas da pesquisa, abordando os significados que os indivíduos ou grupos atribuem ao problema. A natureza dos objetivos baseia-se em pesquisa não estruturada de caráter exploratório, que tem como objetivo auxiliar na compreensão da situação-problema enfrentada pelo pesquisador (MALHOTRA, 2012).

O estudo de caso foi escolhido como estratégia de pesquisa, visando a compreensão aprofundada da aplicabilidade dos conceitos de Inteligência na inserção de uma nova IES no mercado competitivo. O estudo de caso é apropriado para se ter uma apreensão das relações sociais quando se procura entender situações complexas (YIN, 2016). Trata-se de uma 
investigação empírica que se aprofunda em um fenômeno contemporâneo dentro do seu contexto, especialmente quando não estão claramente definidos.

Para a coleta de dados optou-se por entrevistas semiestruturadas como fonte essencial de evidências onde um respondente é questionado para descobrir motivações, crenças, atitudes e sentimentos subjacentes sobre um tema específico (MALHOTRA, 2012). Para Gil (2008), a entrevista semiestruturada é flexível e permite ao pesquisador adaptar e explorar melhor suas questões de interesse no curso da entrevista, ao mesmo tempo em que mantém certo nível de estruturação da mesma. A coleta foi realizada em novembro/2016, seguindo um roteiro semiestruturado, por meio de entrevistas em profundidade com os diretores do Instituto A, que optaram por manter em sigilo o nome da organização. Os questionamentos basearam-se no uso da GI e GC no processo de monitoramento e nas pessoas envolvidas, bem como a aplicabilidade da Inteligência na criação e inserção da IES. As questões foram realizadas individualmente, e as entrevistas foram submetidas à análise de conteúdo para identificação dos conceitos que constituíram as bases desta pesquisa.

A observação participante também foi utilizado como complemento de pesquisa, visto que uma das autoras deste trabalho participa do projeto da nova IES desde o início do processo, atuando no Setor de Relacionamento com o Mercado do Instituto A. Esta técnica de pesquisa é menos estruturada, mas primazia a experiência pessoal vivida no estudo (MACEDO E MACEDO DE SÁ, 2018). Abib, Hoppen e Junior (2013) complementam que a observação participante é uma estratégia de pesquisa que facilita a coleta de dados no campo, que combina o papel do pesquisador (participante de algum modo) com técnicas de coleta de dados (observação), em um processo de aprendizagem pelo envolvimento nas atividades cotidianas de quem participa da pesquisa. Conforme Martins (1996), o grau de aprofundamento desta técnica é capaz de clarear situações e momentos, a partir de um ponto de vista que não seria possível com outra técnica, visto que o observador está inserido no contexto a ser estudado. Neste sentido, o observador atua de forma intensiva a ponto de fazer parte da situação social (HAGUETTE, 2005), o que facilita a análise baseada na experiência do observador no assunto, neste presente estudo, a aplicabilidade da Inteligência Estratégica na criação e inserção de uma IES no mercado.

\section{Apresentação e análise dos resultados}

A Insituição A, sediada em Porto Alegre/RS, oferece serviços de qualificação profissional em todo território nacional, nas modalidades presenciais e a distância. Estruturalmente está organizada em 3 setores: Administrativo Financeiro, Relacionamento com o Mercado e Ensino. O quadro de colaboradores é composto por vinte e cinco funcionários, dois diretores, um deles sócio do Insituto, e o Conselho Diretivo, composto por cinco membros. Atuando no mercado de nutrição e saúde há mais de 8 anos, a Insituição A tem um forte concentimento a tendências organizacionais e novos processos, facilitando assim o trabalho de pesquisa desse projeto. Entretanto, a implantação da IES permanece em sigilo tanto para colaboradores como para sociedade.

Entrevistas foram realizadas com intenção de compreender o entendimento dos dois diretores sobre Inteligência e suas percepções quanto a aplicação do conceito na criação da IES, bem como as pessoas e processos envolvidos. Quanto ao entendimento sobre Inteligência, os entrevistados julgaram não ter clareza conceitual ou técnica do assunto, entretanto, informaram que, através da vivência com o Setor de Relacionamento com o Mercado (setor responsável pela prática de Inteligência no Instituto A), compreendem "Inteligência como uma visão estratégica interna e externa da organização, fazendo contrapontos com os movimentos de mercado e concorrência e das necessidades do consumidor com aquilo que a instituição é capaz 
de oferecer. Buscando sempre melhorar, aprimorar e continuar competitiva" explica um dos diretores, retomando o conceito de Maróstica (2014), que aborda a visão diferenciada do que a Inteligência Estratégica proporciona para que as organizações mantenham-se competitivas no mercado.

Entretanto, há uma controvérsia entre o conceito entendido pelos diretores e a prática da Inteligência no Instituto A. Questionados sobre a existência da Inteligência no Instituto, houve um concenso nas respostas, sinalizando que o "setor existe de forma caseira, sendo um processo novo no Instituto", afirmam os diretores. Relacionando o conceito à prática, a Inteligência não se faz presente, visto que é necessário um processo estruturado de monitoramento e coleta de informações para que a Inteligência seja considerada.

Explicando a rotina da Inteligência no Instituto A, os diretores apontam que os "processos" são demandados pela diretoria de forma não estruturada. Um dos entrevistados associa Inteligência à tecnologia, afirmando que não há um sistema tecnológico em pleno funcionamento. Conforme uma das autoras, que está inserida no projeto e realizando a observação participante, o posicionamento dos diretores está coerente com a realidade da Inteligência no Instituto: a inexistência de um sistema de informações e solicitações não estruturadas e sob demanda que impedem um monitoramento constante de informações.

Questionados sobre as pessoas envolvidas no processo, as respostas foram unânimes, citando apenas a supervisora do setor de Relacionamento com o Mercado como responsável pelo desenvolvimento do setor. Salientaram também os membros do Conselho Diretivo, que muitas vezes atuam como direcionadores de demandas. Entretanto, não foram mencionadas as demais lideranças do Instituto A, que contribuem para a criação do conhecimento, abastecendo principalmente o Conselho com informações relevantes sobre os negócios do Instituto. Neste ponto, a prática é o oposto ao conceito explanado por Strauhs (2012) referente à Gestão do Conhecimento, um dos alicerces da Inteligência, que considera o conhecimento individual e coletivo como um ativo valioso para a geração de insights e tomada de decisão.

Questionados sobre tecnologia, os diretores a relacionam fortemente à Inteligência. Ambos entrevistados ratificam ser "fundamental" para processos bem estruturados, entretanto, na atual realidade do Instituto A salientem como "item de apoio". Reconhecem, contudo, que é um atributo facilitador e essencial, e vislumbram a necessidade e atenção a tecnologias mais apuradas, já implantadas no Instituto, mas ainda não utilizadas.

Quanto aos processos de Inteligência para a criação da IES, um dos diretores destaca os processos desenvolvidos pelo setor de Relacionamento com o Mercado, sinalizando que, embora não estruturado, identificou um cenário futuro e de risco ao principal negócio do Instituto A. Após detectar esse fator, a Instituição buscou auxílio de uma consultoria externa. Tal comportamento, aproxima-se do conceito da Inteligência Antecipativa, que propõe um olhar para o futuro, analisando às mudanças do ambiente externo que podem comprometer o negócio da empresa (LESCA e JANISSEK-MUNIZ, 2015). O diretor ainda complementa que para a criação da IES não há nada estruturado, explicando que as demandas devem surgir conforme o andamento do projeto, visto que a expansão do Instituto A para IES é sigilosa, e está em vias de construção.

O outro respondente, resgatou apenas o processo desenvolvido pela consultoria externa, sem mencionar o setor de Relacionamento para fins de aplicação da Inteligência, especificamente na criação da IES. Na visão de observção participante, como o mercado educacional, em todos os niveis, se relacionam para fins de monitoramento, análise e compreensão de cenários, muitos estudos desenvolvidos e analisados pelo setor de Relacioanmento com o Mercado, foram utilizados de forma complementar para tomada de decisão de implantar a IES. 
Quanto ao monitoramento do mercado de IES, os respondentes concluíram "não existir de forma sistemática", atrelando o monitoramento à fase de implantação da IES, que envolve "processos relacionados à estrutura física e papéis burocráticos", não demandando periodicidade. Os respondentes retomam as informações oriundas da consultoria externa, que julgam "ainda ser válidas a para tomada de decisão". Percebe-se que há uma controvérsia entre o que é percebido pelos respondentes do que é Inteligência e de como ela pode ser aplicada. Ainda que a IES esteja em fase inicial junto às entidades pertinentes, o monitoramento não é realizado, sendo considerado apenas informações e dados coletados de uma consultoria externa, sem continuidade ou sistematização. Considerando Inteligência como um olhar estratégico, é apropriado que esse olhar seja contínuo, independente da fase de implantação, visto que sem monitoramento a Inteligência é incipiente. Independente disto, é fundamental o acompanhamento do macro e microambiente, mesmo com informações já discutidas e analisadas, visto que o mercado está em constante movimento, e que insights prospectados agora podem ser determinantes nos encaminhamentos futuros e na tomada de decisão.

Os fatores relevantes para criação da IES, para um dos respondentes, tiveram origem nos monitoramentos e análises de mercado pertinentes ao negócio principal do Instituto A, que abriram a possibilidade de implantar um novo negócio (IES). Um dos respondentes afirma que "foram consideradas informações subjetivas de caráter qualitativo e dados quantitativos, adquiridos através dos processos internos do setor de Relacionamento com o Mercado e do conhecimento de professores e consultores envolvidos com o Instituto". Perante a subjetividade das informações, foi percebida a necessidade de uma consultoria educacional para fazer um estudo aprofundado, trazendo dados concretos. Informações e dados foram analisados e discutidos tanto para criação da IES quanto para cursos que serão oferecidos. Nota-se que a GI não fica definida se acontece de forma estruturada, mas há uma demanda recorrente de busca tanto de informação como de dados. Pelo teor das respostas, percebe-se desconhecida a diferença entre dados, informação e conhecimento, conforme Davenport e Prusak (1998), e de como a compreensão destes fatores pode agregar à Inteligência.

Quanto à análise e disseminação de informações, os respondentes concluíram que apenas são debatidas, afirmando que "todas as informações são discutidas apenas entre o Conselho Diretivo, não havendo outro momento de debate, análise ou apresentação para as demais pessoas que abastecem o Conselho com informações". Novamente, atrelando a fase de credenciamento da IES, mencionam que não há uma periodicidade nas discussões sobre o novo projeto, mas que está previsto um planejamento para o próximo ano, que pauta informações referente à IES em periodicidade semanal. Não há uma observação sobre cenários futuros, as informações pontuadas são oriundas de uma projeção de 5 anos realizada pela consultoria externa, embasada em dados quantitativos e informações de mercado. Reforça-se que atualmente não há, por parte do Instituto A, um monitoramento de mercado, apenas um acompanhamento das informações trazidas pela consultoria externa.

Através da análise proposta, é possível perceber que houve uma intenção de Inteligência Estratégica, no entanto, embasados em conceitos teóricos, a Inteligência só será legítima quando acompanhada de um monitoramento sistemático do ambiente. Ainda que sejam identificados os monitoramentos, os mesmos são solicitados sob demanda, não sendo contínuos, embora existam indícios de processos semiestruturados de Inteligência Competitiva e Antecipativa. Considerando a Inteligência Estratégica incipiente na Instituição, a alta direção está em sinergia com o que é proposto no setor de Relacionamento com o Mercado, mas ainda não percebe o envolvimento direto de colaboradores que foram ouvidos para a construção da IES. Percebe-se também um congelamento de informações, visto que ainda são analisadas pesquisas, dados e informações extraídas da consultoria externa, o que é arriscado, pressupondo que a consultoria tem certa validade. Há a necessidade de um monitoramento mais abrangente 
envolvendo os colaboradores do Instituto, bem como o envolvimento de outros setores, visto que todas as lideranças têm condições técnicas de contribuir com a construção de conhecimento do negócio atual e novo do Instituto A.

A Inteligência aplicada à IES está diretamente relacionada à fase de credenciamento, considerada burocrática, limitada a algumas atividades e envolvimento de pessoas, visto que é um negócio ainda sigiloso, inclusive para alguns colaboradores do Instituto A. Há uma projeção e um forte incentivo à Inteligência por parte da alta direção, que salienta demandar das pessoas, dos processos e da tecnologia um processo mais estabilizado.

\section{Considerações finais}

Neste artigo foi proposto um estudo para compreender a aplicabilidade da Inteligência Estratégica na criação de uma Instituição de Ensino Superior (IES) do Instituto A. Para tanto, foram designados objetivos específicos para compreender a Inteligência utilizada no Instituto, identificar os processos de monitoramento, identificar as pessoas/setores envolvidas na Inteligência e entender a aplicabilidade da Inteligência na criação da IES.

Em relação ao diagnóstico da situação atual foi constatado que a empresa compreende Inteligência de forma conceitual, mas não aplica, sendo incipiente a área de Inteligência para criação da IES. Quanto ao monitoramento de mercado, a empresa associa ao fato de o projeto estar em fase de credenciamento, não havendo necessidade de um acompanhamento de mercado sistemático, mas é possível identificar processos, não estruturados e somente sob demanda, já permanentes no Instituto A, envolvendo minimamente a criação da IES.

Referente às pessoas envolvidas na atividade de Inteligência no Instituto $\mathrm{A}$, apenas um setor é apontado como responsável pela "operação" da Inteligência e o Conselho como direcionador dos processos. Entretanto, a empresa não descarta informações e conhecimentos recebidos através do pessoal interno do Instituto, bem como parceiros, professores e consultores. Quanto à aplicabilidade da Inteligência na criação da IES, é apontada como fator decisivo, pois foi através do monitoramento que despertou a intenção da criação da IES. Contudo, o projeto da nova IES não conta com monitoramento contínuo e nem processos estruturados, visto que a principal fonte de informação está atrelada a uma consultoria externa. Existe, contudo, previsão de demanda interna de Inteligência.

Em razão da grande expectativa de crescimento com a criação da IES, da necessidade de um monitoramento sistemático para uma inauguração com posicionamento consistente e competitivo, e também diminuição de riscos e incertezas na criação da IES, recomenda-se que o monitoramento seja sistemático, mesmo se já aportado de informações e embasado em pesquisas e análises de consultoria externa. Recomenda-se reuniões periódicas para discussão dos cenários, análises e insigths sobre o novo negócio, e participação de colaboradores do Instituto A para a construção de um conhecimento mais rico em informação interna da empresa, o que permitirá contrapontos da concorrência e do mercado, gerando assertividade no que a empresa está propondo. Considerando a fase em que o processo de criação da IES está, ainda sigilosa para colaboradores e para a sociedade, é também pertinente o acompanhamento mais aprofundado quando a notícia for disseminada, visto que o Instituto é conhecido no mercado educacional. Contudo, sugere-se que esse estudo seja revisado após o lançamento da IES, em vias de consagrar a relevância desta pesquisa. Assim, o estudo aqui apresentado contribui para aprofundar o conhecimento em Inteligência, bem como a sua aplicabilidade prática na criação de uma instituição de ensino. Através do estudo foi possível ilustrar conceitos referentes à Inteligência e os processos que a cercam, bem como uma revisão de Gestão de Informação e Gestão do Conhecimento que corroboram com a ideia de Inteligência Estratégica. 
Referências

ABIB, G.; HOPPEN, N.; JUNIOR, P. H.; Observação Participante em Estudos de Administração da Informação no Brasil. São Paulo, 2013

ABRAIC. Disponível em: <http://www.abraic.org.br>. Setembro de 2016.

BRYMAN, A. Quantity and quality in social research. London: Routledge, 2000.

CARVALHO, A.R.M; CASAGRANDE, R.M. Instituições de Ensino Superior: Um Estudo Sobre a Adequação das Gestões do Conhecimento e da Informação na Busca de Ferramentas Para Inteligência Competitiva. Florianópolis, 2009.

CHOO, C. W. A Organização do Conhecimento: como as organizações usam a informação para criar significado, construir conhecimento e tomar decisões. São Paulo: Senac, 2003.

COSTA, C. J.; COCHIA, C. B. R. A expansão do ensino superior no Brasil e a educação a distância. Revista Teoria e Prática da Educação, v16, n1, p 21-32, Jan/Abr 2013.

CRESWELL, J. W. Investigação qualitativa e projeto de pesquisa escolhendo entre cinco abordagens. $3^{\mathrm{a}}$ ed. Porto Alegre: Penso, 2014.

DALFOVO, O; SCHIRMANN, F. R; CORREIA R. B. A Utilização do Observatório da Educação como Inteligência Competitiva em uma IES. Florianópolis, 2011.

DAVENPORT, T. H e PRUSAK, L. Conhecimento Empresarial. Campus, 1998.

DEL MASSA, H. C.O.; DAMIAN, I. P. M.; VALENTIM, M. L. P. Competência Em Informação No Apoio À Gestão Do Conhecimento, João Pessoa, 2018

FULD, L. M. Inteligência competitiva: Como Se Manter à Frente dos Movimentos da Concorrência. Rio de Janeiro: Editora Campus, 2007.

GIL, A. C. Métodos e técnicas de pesquisa social. 6. Ed. São Paulo: Atlas, 2008.

GOMES. E; BRAGA, F. Inteligência Competitiva. Rio de Janeiro: Campus, 2004.

HAGUETTE, T. M. F. Metodologias qualitativas na sociologia. Petrópolis: Vozes, 2005.

HEINZE, M.; JANISSEK-MUNIZ, R. A Inteligência Estratégica associada a Capacidade de Inovação. Porto Alegre, 2018.

KRIAA, S., JANISSEK-MUNIZ, R. e LESCA, H. Identificação de Competências para a Animação da IEAc. Congresso IFBAE, Anais, Gramado, 2015.

LEITÃO, P. C.C. Informação, concorrência e processo decisório em IES. BH, 2010.

LESCA, H., JANISSEK-MUNIZ, R. Inteligência Estratégica Antecipativa e Coletiva: O Método de L.E.SCAnning. Porto Alegre: Pallotti, 2015.

MACEDO, R. S., MACEDO DE SÁ, S. M. A Etnografia Crítica Como Aprendizagem E Criação De Saberes E A Etnopesquisa Implicada: Entretecimentos. Currículo sem Fronteiras, Bahia, 2018.

MALHOTRA, N. K. Pesquisa de marketing: uma orientação aplicada. Bookman, 2012.

MARÓSTICA, E. Inteligência de Mercado. São Paulo: Cengage Learing, 2015

MARTINS, J. B. Observação participante: uma abordagem metodológica para a psicologia escolar. Semina: Ci. Sociais/Humanas, 1996

MEC. O Ensino Superior no Mundo e no Brasil. Brasília, 2003.

MEC/INEP. Censo de Educação Superior 2017: Notas Estatisticas. Brasília, 2018.

NONAKA, I; TAKEUCHI, H. Dados eletrônicos. Porto Alegre: Bookman, 2008.

RECHE, M. M.; JANISSEK-MUNIZ, R. Inteligência Estratégica e Design Thinking: Conceitos Complementares, Sequenciais e Recorrentes para Estratégia Inovativa. Porto Alegre, 2018 
RIOS. F.L.C; JANISSEK-MUNIZ, R. Uma Proposta de Relação de Requisitos Funcionais para um Software de Apoio ao Processo de Inteligência. Read, Porto Alegre, 2014.

SANTOS, I. M.; BARBOSA, C. R.; Ciência da Informação e Inteligência de Estado: Relações Entre a Gestão da Informação e do Conhecimento e a Proteção do Conhecimento Sensível. Bahia 2016.

SANTOSA, H. S.; RIBASB, F. T. T.; Inteligência Estratégica Na Conquista de Novos Mercados. Caxias do Sul, 2017

STAREC, C. Gestão da Informação, inovação e Inteligência Competitiva. Saraiva 2012. STRAUHS, F.R. Gestão do Conhecimento nas Organizações. Curitiba: Aymará, 2012. SILVA, R.V. e NEVES, A. Gestão de Empresas na Era do Conhecimento. Lisboa, 2003. TARAPANOFF, K. Inteligência, Informação e Conhecimento. Brasília, Unesco, 2006. VENKI. Gestão do Conhecimento: Pessoas, processos e tecnologia. Disponível em <http://www.venki.com.br/blog/pessoas-processos-tecnologia/> setembro de 2016. VENTURINI, J; DINIZ, B.; MORALES, R; FLECK, C. JUNIOR, Z.; NAGEL, M. Percepção da avaliação: retrato da gestão pública de uma IES. Rio de Janeiro, 2010.

YIN, R. K. Pesquisa qualitativa do início ao fim. Porto Alegre: Penso, 2016. 